www. revistad yo. com

\title{
Demand Driven MRP - Nuevo método para la gestión de la Cadena de Suministro: un estudio de caso
}

\author{
Kortabarria A, Apaolaza U, Lizarralde A
}

Recibido: 20 de Julio de 2018 / Aceptado: 25 de Septiembre de 2018

\section{Resumen}

La metodología Demand-Driven Material Requirement Planning (DDMRP) fue desarrollado con el objetivo de aumentar el flujo de materiales e información de una cadena de suministro y así mejorar la ventaja competitiva de esta. En la revisión de la literatura se han identificado trabajos de investigación que analizan el funcionamiento de esta metodología en entornos simulados. Sin embargo, no se han encontrado estudios que analicen la implementación del DDMRP en una empresa real. El presente trabajo, por lo tanto, analiza la evolución que una empresa que fabrica componentes para electrodomésticos obtuvo al migrar del MRP al DDMRP.

Los resultados obtenidos, demuestran que gestionando los materiales con la metodología DDMRP la empresa aumentó la visibilidad en la cadena de suministro reduciendo considerablemente el efecto bullwhip y los pedidos urgentes. Cabe destacar también la evolución del inventario, ya que el stock físico se redujo mientras que el consumo de los materiales aumentó. Durante todo el proceso el nivel de servicio de la empresa se mantuvo prácticamente en un $100 \%$.

\section{Palabras clave}

DDMRP; Inventario; Visibilidad; Previsiones; Incertidumbre.

\section{Introducción}

En la década de1960 a 1970 las empresas principalmente competían bajo una estrategia basada en el coste, por lo que los procesos de fabricación estaban diseñados para fabricar en entornos estables con lotes grandes y con el principal objetivo de reducir costes. Sin embargo entre 1960 y 1980 el mercado cambió y la calidad comenzó a adquirir protagonismo (Rondeau and Litteral, 2001). Es decir el mercado comenzó a solicitar productos personalizados que debían satisfacer las necesidades específicas de los clientes (McKenna, 1990).

Este nuevo rumbo creó la necesidad de atender y gestionar constantes cambios en la programación de la producción (Rondeau and Litteral, 2001). Acortar tiempos de producción, reducir los inventarios, ampliar el catálogo

\footnotetext{
Alaitz Kortabarria*

akortabarriai@mondragon.edu

https://orcid.org/0000-0001-5298-0942u

Unai Apaolaza*

uapaolaza@mondragon.edu

https://orcid.org/0000-0003-3257-9291

Aitor Lizarralde*

alizarralde@mondragon.edu

https://orcid.org/0000-0002-1390-9817

*Dpto. de Mecánica y Producción Industrial. Mondragon Unibertsitatea. Loramendi 420500 Arrasate-Mondragón Gipuzkoa.,
}

de productos, cumplir con las fechas de entrega, mejorar la calidad del producto así como el nivel de servicio ofrecido a los clientes pasaron a ser claves para conseguir una ventaja competitiva sostenible en el tiempo (Cox and Schleier, 2010).

Sin embargo, alcanzar y conservar esta ventaja competitiva resulta un reto exigente para las empresas, ya que el importante incremento de la incertidumbre generado por la variabilidad de la demanda, hace que los modelos de planificación basados en previsiones sean incapaces de identificar las necesidades reales (Smith and Smith, 2013a).

Ante este escenario las empresas han realizado inversiones significativas en infraestructura, tecnología y nuevos enfoques de gestión (TOC, Lean, MRP). Estas inversiones han contribuido a poseer cadenas de suministro cada vez más eficientes en coste. Sin embargo, a pesar de las mejoras en las herramientas disponibles, los indicadores de Retorno Sobre la Inversión (ROI) no mejoran, un porcentaje alto de los clientes siguen insatisfechos y los inventarios siguen siendo altos y no están alineados con la demanda real causando una distribución Bi-Modal (Fig. 1a) (Smith and Smith, 2013b).

Según Ptak and Smith (2016) los Sistemas de Planificación y Control de la Producción (SPCP) deben promover la estrategia de fabricación orientada a la demanda. Deben suministrar flexibilidad y visibilidad de las necesidades reales para que la empresa se ajuste a ellas y pueda tomar decisiones correctas de una manera simple, convirtiéndolas en una empresa ágil. 
Considerando esta realidad, Ptak and Smith (2011) desarrollaron un nuevo SPCP capaz de responder al mercado volátil, promover la estrategia de fabricación orientada a la demanda y realinear el inventario de forma estratégica, para así disponer del inventario requerido para atender la demanda real (Fig. 1b).

Figura 1 (a) Distribución Bi-Modal

y (b) realineación estratégica del

inventario
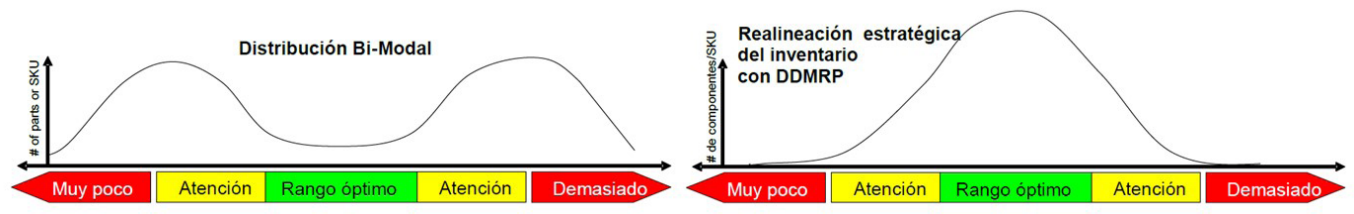

\subsection{Demand Driven MRP}

DDMRP incorpora funcionalidades del MRP, Lean, TOC, Seis Sigma, Distribution Resource Planning (DRP) así como conceptos innovadores permitiendo planificar y controlar el flujo de materiales de una cadena de suministro. A continuación, se describen los cinco pasos de los que se compone el DDMRP.

1. Posicionamiento estratégico del inventario: Disponer de inventario en toda la cadena de suministro supone un gran derroche de recursos para la empresa. Sin embargo, eliminar completamente el inventario conlleva riesgo a la hora de gestionar suministros y demandas que varían en el tiempo. DDMRP propone 6 factores para poder identificar la ubicación idónea del inventario en una cadena de suministro. De esta forma, el inventario permite desacoplar los procesos, convirtiéndolos independientes y absorber tanto la variabilidad de la demanda como la del suministro, evitando la transmisión de la incertidumbre a través de la estructura de los materiales causada por el MRP (Ptak and Smith, 2016).

2. Perfiles y niveles de buffer: Una vez de posicionar el inventario en la estructura de materiales es necesario dimensionarlos. Para ello DDMRP se basa, entre otros aspectos, en el consumo medio diario real de las referencias, el lead time de estas o la existencia o no de una cantidad mínima de pedido definida. De esta forma los buffers se dimensionan considerando la demanda real y no en base a previsiones erróneas.

3. Ajustes dinámicos: Debido a los constantes cambios del mercado, es importante reajustar la dimensión de los bufferes para poder funcionar correctamente ante nuevas realidades. Es decir, es posible que el consumo de una referencia varíe en el tiempo, por lo que el buffer de esta referencia debería adecuarse a estas variaciones para que la empresa sea capaz de atender las necesidades reales de esa referencia. DDMRP proporciona funcionalidades que permiten ajustar los bufferes según las necesidades del momento.
4. Planificación basada en la demanda: Este cuarto paso permite planificar la necesidad de materiales y lanzar órdenes de compra/producción según el tipo de referencia. Para ello, DDMRP ha desarrollado el concepto de Flujo Neto, que se calcula considerando el stock físico, órdenes de compra abiertas y la demanda real. Cuando el valor de esta variable alcanza la zona de reposición del buffer, la empresa debe planificar una orden de compra/producción hasta el nivel máximo del buffer correspondiente. Para facilitar dicha tarea, el DDMRP muestra la posición del Flujo Neto de cada buffer a través de una alerta codificada por colores. Este hecho permite identificar de forma sencilla e intuitiva las referencias que deben ser reaprovisionadas.

5. Ejecución visible y colaborativa: Una vez planificadas las órdenes, es importante controlarlas para asegurarse de que todo avanza según lo previsto. DDMRP incorpora diferentes alertas codificadas por colores que permiten realizar el seguimiento de estas órdenes. En caso de que algo se desvíe de lo planificado, esta se muestra a través de dichas alertas. Así el responsable identifica de forma sencilla qué referencias se encuentra en situación crítica y requieren atención. Esta ejecución permite a la empresa a priorizar las referencias de forma correcta y sencilla basándose en el estado de penetración de los bufferes, evitando así la generación de prioridades erróneas basadas en la fecha de vencimiento.

Hasta el momento varios autores han estudiado y simulado el comportamiento del DDMRP. A continuación se resumen los trabajos identificados hasta el momento:

- Lee and Jang (2013) a través de la simulación calcularon el nivel de inventario requerido por tres empresas tras gestionar los materiales con DDMRP.

- $\quad$ En el 2014 estos mismos autores publicaron la tesis que tenía como objetivo analizar el rendimiento del DDMRP y compararlo con el MRP (Lee and Jang, 2014).

- Ihme (2015) desarrollo un modelo de simulación para analizar la gestión de los materiales basándose en la 
metodología DDMRP y comparó los resultados obtenidos con aquellos que la empresa estaba obteniendo utilizando el MRP.

- Ihme and Stratton (2015) simularon y analizaron el potencial de mejora que una empresa de fabricación de tintas de impresión obtendría gestionando los materiales con DDMRP.

- Miclo et al. (2015) basándose en la simulación de eventos discretos, realizaron una comparación cuantitativa entre el MRP y DDMRP.

- Miclo (2016) elaboró una tesis cuyo objetivo era simular y comparar el funcionamiento y los resultados de dos casos de estudio utilizando MRP, Kanban y DDMRP.

- Shofa and Widyarto (2017) analizaron el nivel de inventario que una empresa automotriz de Indonesia requeriría gestionando los materiales con el DDMRP y el MRP.

- Miclo et al. (2018) a través de modelos de simulación analizaron el DDMRP, el MRP II y Kanban / Lean production y compararon los resultados obtenidos.

Todos los trabajos de investigación identificados hasta el momento simulan el funcionamiento del DDMRP en diferentes entornos. Sin embargo, no se han encontrado estudios que analicen la evolución de una empresa real tras la implantación del DDMRP. Por lo tanto, el presente trabajo de investigación analiza el proceso de implantación del DDMRP en una empresa real y los resultados obtenidos gestionando el flujo de los materiales con esta novedosa metodología.

El resto del artículo se ha estructurado de la siguiente manera: En el siguiente punto se presenta el caso de estudio. En primer lugar, se describe la empresa donde el DDMRP fue implantado para a continuación exponer los aspectos críticos que dificultaban el flujo de materiales. Después se resume el proceso de implantación del DDMRP y los resultados obtenidos. En el último punto se presentan las conclusiones y líneas futuras de investigación identificadas.

\section{Estudio de caso}

\subsection{Introducción y problemática}

La implantación del DDMRP se realizó en una empresa internacional que desarrolla componentes para electrodomésticos. Antes de la implantación del DDMRP, la empresa planificaba la necesidad de materiales utilizando el MRP. La empresa tenía un alto nivel de servicio, pero mantener este nivel de servicio le suponía un gran coste económico, ya que para hacer frente a la gran variabilidad existente necesitaba gran volumen de inventario. Aun así, la empresa sufría constantes roturas de stock. Para evitar futuras roturas de stock, la empresa incrementaba el stock de seguridad de las referencias.

Considerando esta situación, la empresa (en adelante CS1), se planteó cambiar de sistema de planificación e implantar el DDMRP. Por motivos internos que trascienden el alcance de este estudio, la empresa decidió gestionar únicamente la materia prima con el DDMRP y mantener el sistema original para programar la producción.

Durante el proceso de implantación los implantadores del DDMRP identificaron varios aspectos que dificultaban el flujo de materiales e información a lo largo de la cadena de suministro que se resumen a continuación:

- Cambio de la programación de la producción a nivel local: CS1 disponía de un sistema para programar la producción que, considerando las previsiones reportadas por los clientes, programaba la producción de los siguientes cinco días. El sistema no permitía en ningún caso modificar el programa. Sin embargo, debido a la variabilidad de la demanda de los clientes, el responsable de la producción identificaba tareas programadas que ya no eran necesarias o referencias demandadas y que no estaban programadas para ser producidas. Para poder incluir estos ajustes, el responsable de producción desarrolló una hoja de cálculo que modificaba el programa de producción de forma local. No obstante, estos cambios no se plasmaban en el sistema de Planificación de Recursos Empresariales (ERP). Esta desincronización de la información generaba roturas de stock, ya que CS1 no era consciente de la necesidad de esa materia prima hasta comenzar a producir. Para solventar este tipo de situaciones el acopiador de materiales gestionaba pedidos urgentes y así podía disponer del material requerido a la mayor brevedad posible. Además, a menudo el acopiador de materiales solía aumentar el stock de seguridad de estas referencias para evitar repetir esta situación en el futuro. Este hecho acentuaba la distribución Bi-Modal del inventario.

- Planificar la producción sin considerar la disponibilidad de la materia prima: El programa de producción era elaborado sin considerar si había disponibilidad de materia prima. Una vez cerrada la programación de la producción, CS1 revisaba la disponibilidad de la materia prima y en caso de no haber suficiente lanzaba una orden de compra de la referencia requerida. No obstante, dependiendo del plazo de entrega de la referencia era posible que ésta no llegara a tiempo. En estos casos el acopiador contactaba con el proveedor para acelerar el pedido y así evitar roturas de stock.

- Sincronización con el calendario de los proveedores: Es frecuente que el calendario laboral de una empresa no coincida con el de sus proveedores o clientes. 
En este caso CS1 debía prever el material a consumir durante el periodo vacacional de los proveedores y adelantar los pedidos para disponer con antelación de material suficiente y producir sin ningún problema. Sin embargo, CS1 tenía dificultades a la hora de estimar la necesidad real de materiales. En caso de prever más material del necesario la empresa sufriría un sobre stock, mientras que una previsión a la baja generaría roturas de stock e interrumpiría la producción.

- Efecto silo con proveedores: CS1 subcontrataba el montaje de ciertos componentes. Para ello compartía las previsiones de los clientes con la empresa subcontratada y realizaba la compra del material requerido para el montaje correspondiente. Debido a la variabilidad de las previsiones, los montajes realizados por la empresa subcontratada no coincidían con las necesidades reales de CS1. Para solventar esta situación, la empresa subcontratada frecuentemente debía rehacer los montajes. En ocasiones esta tarea no era factible debido a que no disponía de materia prima suficiente, sufriendo roturas de stock. Esta desincronización entre CS1 y la empresa subcontratada afectaba directamente en la capacidad de montaje de esta última.

\subsection{Proceso de implantación del DDMRP}

A continuación, se resume el proceso de implantación de la metodología DDMRP en la empresa CS1.

1. Posicionamiento estratégico del inventario: Como se ha mencionado en el apartado anterior CS1 decidió gestionar únicamente la materia prima con el DDMRP. Por lo que el punto de desacoplamiento se ubicó en este eslabón de la cadena de suministro. Cabe mencionar que antes de la implantación del DDMRP, CS1 ya disponía de inventario de materia prima, aunque ésta se gestionaba en base a los criterios del MRP.

2. Perfiles y niveles de buffer: En primer lugar, se analizaron una a una todas las referencias y se decidió cuáles gestionar contra pedido y cuáles contra stock. A continuación, se analizó el patrón de consumo de cada una de las referencias a inventariar para poder asignar el buffer más adecuado y llevar a cabo el dimensionamiento.

3. Ajustes dinámicos: En esta fase se programaron los ajustes que permiten reajustar la dimensión de los bufferes a las necesidades reales de cada momento. Dichos ajustes se calcularon considerando el consumo medio diario de cada referencia y el lead time de los proveedores. De la misma manera se planificaron ajustes que permitieran sincronizarse con el calendario laboral de los proveedores. Para ello, además de las variables antes mencionadas, también se tuvo en cuenta el periodo en el que el proveedor estaba ausente. De esta forma, CS1 era capaz de adelantar las órdenes de compra para así poder disponer de material suficiente y seguir sirviendo los pedidos de los clientes durante el periodo vacacional de los proveedores.

4. Planificación basada en la demanda: Para este punto CS1 ya estaba modelizado en un entorno DDMRP. Para realizar la planificación de los materiales la aplicación que soportaba el DDMRP diariamente calculaba la posición del Flujo Neto de cada referencia permitiendo identificar las referencias que se encontraban en la zona de reposición. De esta forma CS1 diariamente lanzaba las órdenes de compra necesarias.

5. Ejecución visible y colaborativa: La aplicación que soportaba el DDMRP considerando el consumo medio diario y el stock físico, mostraba el estado de penetración de buffer de cada referencia. Dicha aplicación visualizaba este estado a través de alertas de diferentes colores y facilitaba a CS1 a identificar las referencias que se encontraban en un estado crítico y priorizarlas respecto a aquellas que no requerían ninguna acción.

\subsection{Resultados tras la implantación del DDMRP}

Tras gestionar la materia prima siguiendo los criterios de la metodología DDMRP, la empresa desacopló el suministro de materia prima respecto a la producción. Así, CS1 comenzó a planificar las necesidades de materia prima en base al consumo real, ignorando las previsiones. Consecuentemente, un cambio en la programación de la producción de forma local, dejó de ser motivo de rotura de stock, ya que la posición del Flujo Neto era calculada considerando el consumo real, es decir, la producción real. Así, la tarea de planificar órdenes de compra se convirtió en tarea sencilla, intuitiva y ágil. Cabe mencionar que CS1 ya disponía de inventario de materia prima antes del DDMRP. Pero este inventario no estaba ni dimensionado ni gestionado siguiendo la metodología DDMRP, por lo que CS1 era incapaz de obtener estos resultados.

Este inventario estratégico también permitió frenar el efecto bullwhip entre CS1 y la empresa subcontratada, incrementando la visibilidad de la cadena de suministro. Así, la empresa subcontratada comenzó a planificar las necesidades de montaje considerando la posición del Flujo Neto de los bufferes de la materia prima de CS1 e ignorando por completo las previsiones de los clientes. Como resultado de ello, se incrementó considerablemente la capacidad de montaje de la empresa subcontratada manteniendo los mismos recursos.

Utilizando los ajustes dinámicos, CS1 fue capaz de ajustar el nivel de inventario a las necesidades de cada momento. Además, ello también le permitió sincronizarse con el calendario de los proveedores, pues esta función permitió a CS1 planificar ajustes y así gestionar el suministro de materiales 
necesarios para seguir trabajando mientras los proveedores interrumpían el suministro.

Tras la implantación del DDMRP la empresa redujo considerablemente el nivel de inventario. Para realizar un análisis cuantitativo, se consideró interesante observar la evolución de las referencias más estratégicas tras la implantación del DDMRP, en concreto se analizaron 203 referencias. Teniendo en cuenta el lead time de estas referencias, se definió un periodo de estudio de 4 meses para poder así observar varias rotaciones del inventario. En este análisis se midió la demanda de estas referencias, el stock físico en la empresa y la cobertura de stock. co se redujo de media un 24,34\%. La cobertura de stock que muestra el número de días que el inventario permanece en el almacén antes de ser vendido también se redujo $33.47 \%$. Es decir, CS1 pasó de tener de media 15 días de stock a tener 9 días, lo que significa que CS1 incrementó la rotación del inventario (Figura 2). Es importante remarcar que la empresa fue capaz de hacer frente a una demanda mayor con un inventario menor manteniendo el nivel de servicio que la empresa tenía antes de la implantación del DDMRP.

Estos resultados muestran que la empresa fue capaz de ajustar el nivel de inventario a la demanda real, debido a la reducción de la incertidumbre generada por las previsiones.

Durante el periodo analizado, la demanda general de la muestra aumentó de media un 13,94\% mientras el stock físi-

Figura 2 Evolución de (a) el consumo medio diario, (b) stock físico y (c) cobertura de stock de la muestra analizada
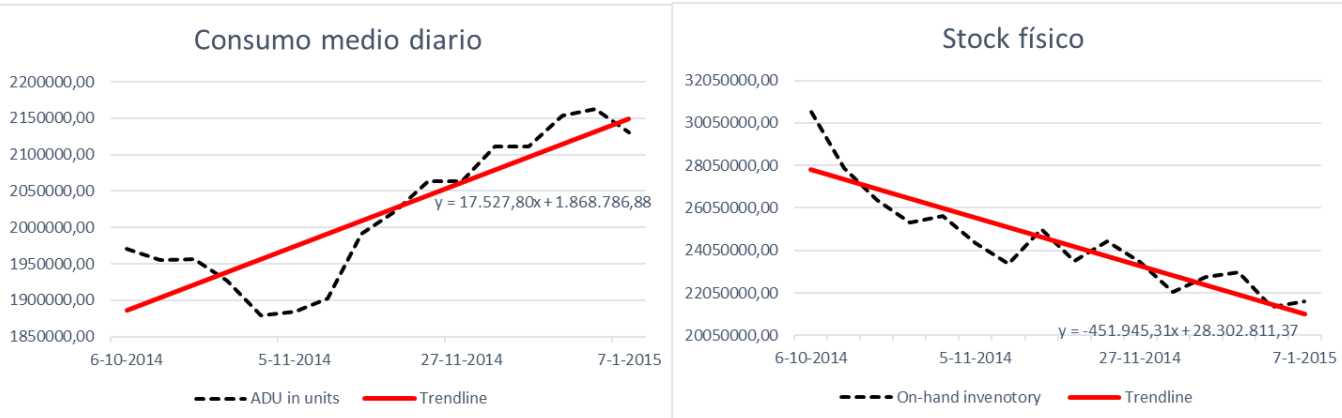

Cobertura de stock

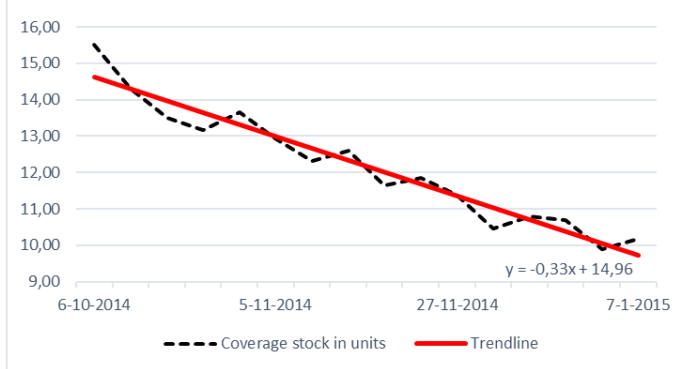

Con el objetivo de realizar un estudio más detallado, las 203 referencias se clasificaron según el lead time (corto, medio o largo) para así poder analizar cada grupo de forma independiente. A continuación, se detalla las características de cada grupo:

- $\quad$ Lead time largo: referencias con lead time mayor a 30 días. En la muestra analizada 10 referencias tenían lead time mayor a 30 días. Estas referencias representaban el $7,15 \%$ del consumo total y el $18.16 \%$ del stock físico total.

- $\quad$ Lead time medio: referencias con lead time entre 11 y 29 días. En la muestra analizada 58 referencias tenían este lead time y representaban el $5.87 \%$ del consumo total y el $13.15 \%$ del stock físico total.
- $\quad$ Lead time corto: referencias con lead time menor a 10 días. En la muestra analizada 135 referencias tenían el lead time menor a 10 días. Estas referencias representaban el $86.98 \%$ del consumo total y el $68.69 \%$ del stock físico total.

Tras realizar el análisis individual de cada grupo, se observó que los tres grupos siguieron el mismo patrón, ya que en los tres casos el consumo total de las referencias aumentó mientras que el stock físico se redujo, incrementando la rotación del inventario. A continuación, se detalla el resultado de cada grupo:

- La cobertura de stock de las referencias con lead time largo se redujo un $51.85 \%$, debido a que en este periodo el consumo de estas referencias aumentó $25.85 \%$ mientras que el stock físico se redujo un 38,16\% (Figura 3). 
Figura 3 Evolución de (a) el consumo medio diario, (b) stock físico y (c) cobertura de stock de las referencias de con lead time largo

- El consumo de las referencias con lead time medio creció un $31.2 \%$ mientras que el stock físico se redujo un $11.63 \%$. Como resultado estas referencias aumentaron
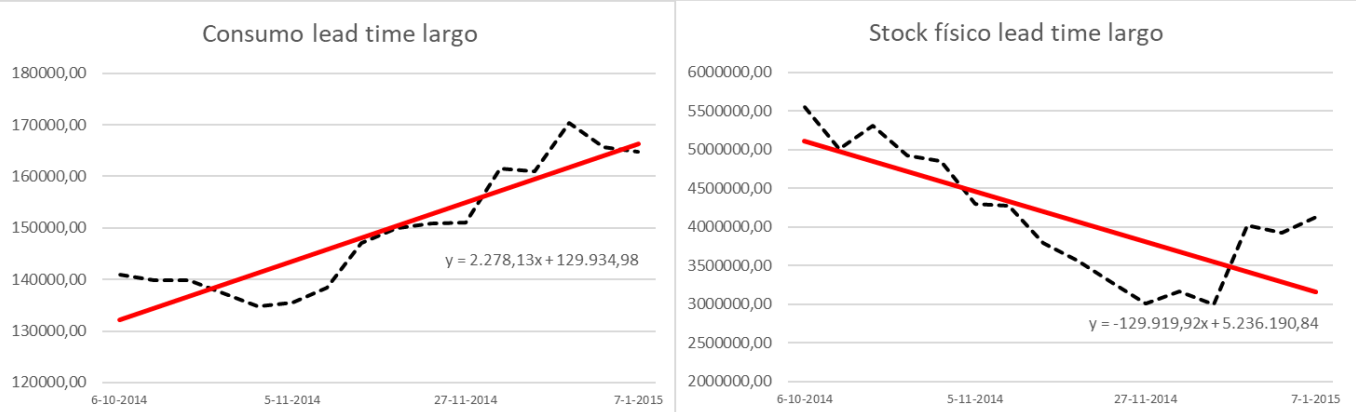

Cobertura de stock lead time largo

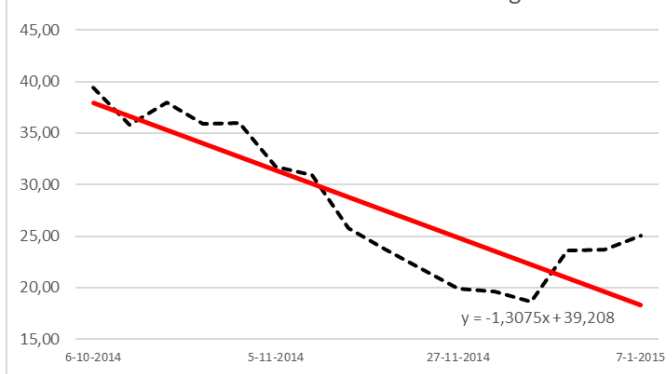

su rotación ya que pasaron de 30 a 20 días de stock (Figura 4).
Figura 4 Evolución de (a) el consumo medio diario, (b) stock físico y (c) cobertura de stock de las referencias con lead time medio

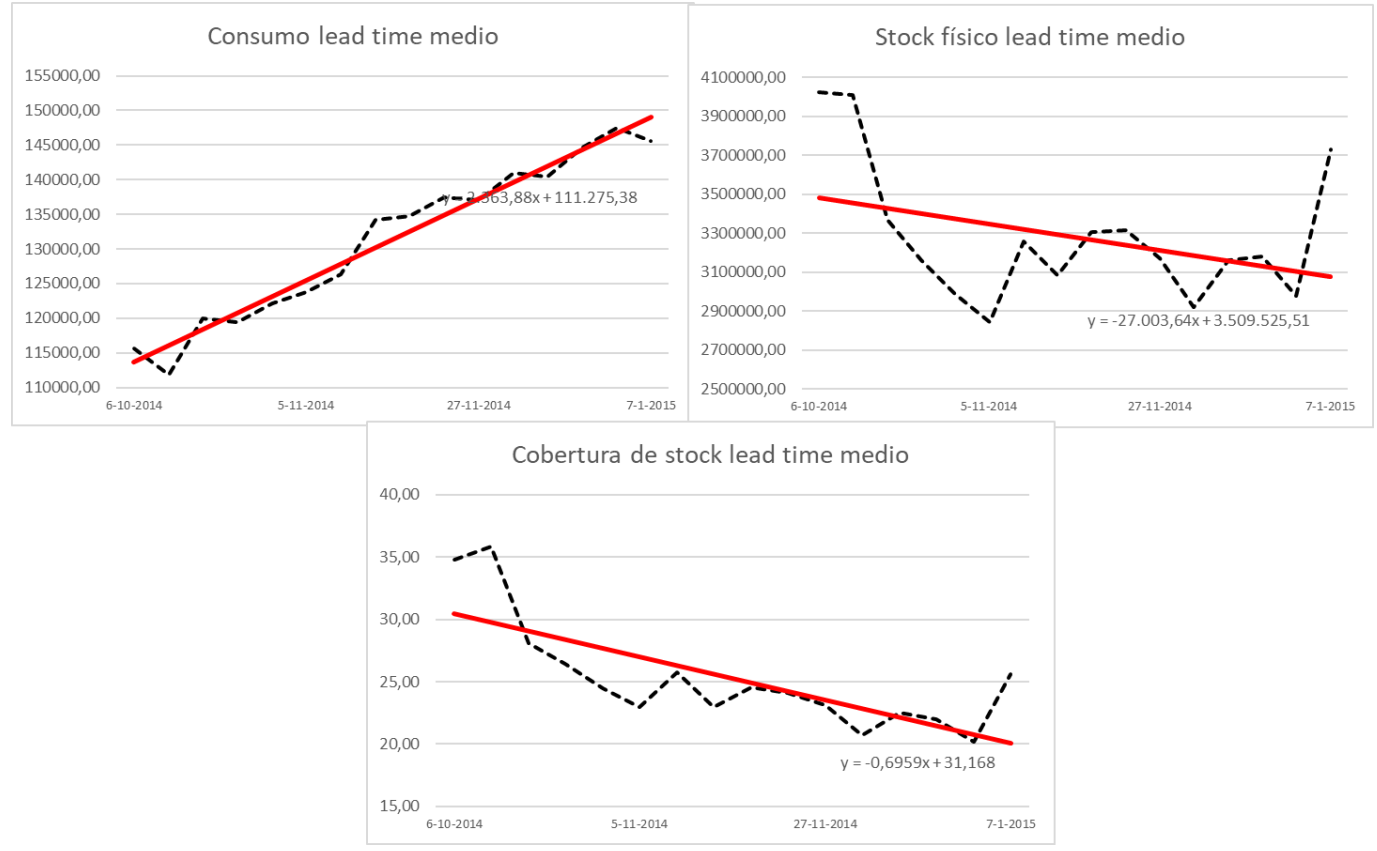


- $\quad$ El consumo de las referencias con lead time corto aumentó un $11.78 \%$ mientras que el stock físico se redujo un $22.97 \%$. Por lo tanto, la cobertura de stock se redujo un $30.93 \%$ (Figura 5).
Figura 5 Evolución de (a) el consumo medio diario, (b) stock físico y (c) cobertura de stock de las referencias con lead time corto

\section{Conclusiones}

Actualmente las empresas se encuentran diariamente remando en entornos volátiles, inciertos y complejos donde una eficiente gestión de la cadena de suministro es clave para conseguir una ventaja competitiva sostenible en el tiempo. Sin embargo, los sistemas de SPCP tradicionales no fueron desarrollados para gestionar este tipo de entornos dinámicos.

Con el objetivo de responder al mercado volátil y promover la estrategia de fabricación orientada a la demanda, se desarrolló el DDMRP. Al considerarse una metodología emergente, existe un número reducido de trabajos de investigación que analicen el DDMRP. Todos los estudios identificados hasta el momento, resaltan los buenos resultados obtenidos utilizando esta metodología en entornos simulados. También recalcan la necesidad de profundizar en el campo e investigar entornos reales donde la gestión de los materiales y producción es realizada utilizando el DDMRP. Considerando esta necesidad, este trabajo de investigación contribuye con un estudio de caso donde se analiza en detalle los cambios realizados y los resultados obtenidos por una empresa internacional que desarrolla componentes para electrodomésticos al pasar de un entorno MRP a un entorno DDMRP.

Los resultados de este estudio muestran que el DDMRP permitió a CS1 ajustar el inventario a la demanda real siendo capaz de atender una demanda mayor con menos inventario. Debido a la eliminación de la incertidumbre en la cadena de suministro, CS1 incrementó su visibilidad, por lo que ya no requería de un gran stock de seguridad para cubrir imprevistos.

Otro de los resultados a destacar fue la sincronización entre los diferentes eslabones de la cadena de suministro. El inventario de materia prima posicionado y gestionado estratégicamente absorbió la variabilidad de la demanda de los clientes aguas arriba. Este hecho permitió a la empresa subcontratada visualizar la demanda real de su cliente y llevar a cabo los montajes solicitados, sin desperdiciar su capacidad realizando tareas no requeridas. Por otra parte, CS1 fue capaz de ubicar la materia prima necesaria en las instalaciones de la empresa subcontratada, evitando el excedente de stock que había antes del DDMRP.

Además, el DDMPR permitió ajustar de forma dinámica los bufferes según las necesidades reales del momento. Incluso permitió gestionar de forma eficiente situaciones especiales y sincronizarse con el calendario de los proveedores.

En resumen, se concluye que el DDMRP ayudó a obtener una ventaja competitiva en términos de resultados logísticos, ya que CS1 fue capaz de ofrecer a sus clientes un mismo nivel de servicio a un menor coste.

Para finalizar, cabe mencionar la necesidad de seguir investigando en el campo, analizando implantaciones del DDMRP en entornos y sectores diferentes. Ya que esto proporcionará más evidencia para verificar en qué medida DDMRP mejora los factores logísticos de las empresas a la vez que proporciona una ventaja competitiva. 


\section{Referencias bibliográficas}

COX, J., III \& SCHLEIER, J. 2010. Theory of constraints handbook, New York, McGraw Hill Professional.

IHME, M. 2015. Interpreting and applying demand driven MRP: a case study. PhD thesis, Nottingham Trent University.

IHME, M. \& STRATTON, R. 2015. Evaluating demand driven MRP: a case based simulated study. International Conference of the European Operations Management Association. Neuchatel, Switzerland.

LEE, J. S. \& JANG, S. Y. 2013. A case study to decide the proper inventory on-hand level based on Demand Driven MRP replenishment buffer. Journal of the Korean Society of Supply Chain Management, 13, pp. 29-42.

LEE, J. S. \& JANG, S. Y. 2014. A system dynamics model to evaluate the performances of MRP and demand driven MRP. Journal of the Korean Society of Supply Chain Management, 14, pp. 125-136.

MCKENNA, R. 1990. Marketing is everything. Harvard Business Review, 69, pp. 65-79.

MICLO, R. 2016. Challenging the" Demand Driven MRP" Promises: a Discrete Event Simulation Approach. PhD thesis, Ecole nationale des Mines d'Albi-Carmaux.
MICLO, R., FONTANILI, F., LAURAS, M., LAMOTHE, J. \& MILIAN, B. 2015. MRP vs. demand-driven MRP: Towards an objective comparison. Industrial Engineering and Systems Management (IESM), 2015 International Conference Seville, Spain: IEEE. doi: http://doi. org/10.1109/IESM.2015.7380288

MICLO, R., LAURAS, M., FONTANILI, F., LAMOTHE, J. \& MELNYK, S. A. 2018. Demand Driven MRP: assessment of a new approach to materials management. International Journal of Production Research, 1-16. doi: http://doi.org/10.1080/00207543.2018.1464230

PTAK, C. \& SMITH, C. 2016. Demand Driven Material Requirements Planning (DDMRP), Industrial Press.

RONDEAU, P. \& LITTERAL, L. A. 2001. The evolution of manufacturing planning and control systems: From reorder point to enterprise resource planning. Production and Inventory Management Journal, 42, pp. 1-7.

SHOFA, M. J. \& WIDYARTO, W. O. 2017. Effective production control in an automotive industry: MRP vs. demand-driven MRP. AIP Conference Proceedings, 1855, pp. 10. doi: http://doi.org/10.1063/1.4985449

SMITH, D. \& SMITH, C. 2013a. Demand Driven Performance, McGraw-Hill Education.

SMITH, D. \& SMITH, C. 2013b. What's Wrong with Supply Chain Metrics. Strategic Finance. 